\title{
Intramuscular myxoma of the thigh: a rare case report
}

\section{SENHAJI Said *; ABDULRAZAK Saeed; KACIMI ALAOUI Mehdi ; EL IDRISSI Mohamed ; EL IBRAHIMI Abdelhalim ; EL MRINI Abdelmajid}

Department of osteoarticular surgery B4, HASSAN II teaching hospital, Fès, Morocco

\begin{abstract}
Myxoma is a rare, benign mesenchymal tumor composed of undifferentiated stellate cells within a myxoid stromaresembling that of the umbilical cord . Apart from cardiac locations, skeletalmuscle involvement is commonly seen around thigh muscles, although other muscles could be affected with intermuscular, para-articular and even subcutaneous subsets. The authors intend to highlight the diagnostic challenge that could arise in the management of what is a benign tumor through a case report and review of relevant literature.
\end{abstract}

\section{Keywords:}

myxoma, benign tumor, thigh
${ }^{*}$ Correspondence to Author:

SENHAJI Said

Department of osteoarticular surgery B4, HASSAN II teaching hospital, Fès, Morocco

How to cite this article:

SENHAJI Said; ABDULRAZAK Saeed; KACIMI ALAOUI Mehdi ; EL IDRISSI Mohamed ; EL IBRAHIMI Abdelhalim ; EL MRINI Abdelmajid Intramuscular myxoma of the thigh: a rare case report.American Journal of Orthopedic Research and Reviews, 2018, 1:6

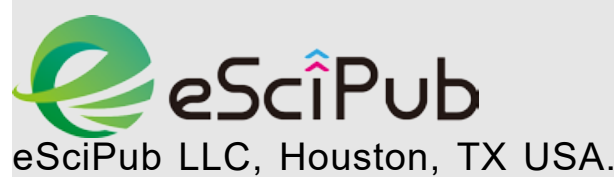

Website: http://escipub.com/ 


\section{Introduction}

Myxoma is a rare, benign mesenchymal tumor composed of undifferentiated stellate cells within a myxoid stromaresembling that of the umbilical cord [1]. Apart from cardiac locations, skeletalmuscle involvement is commonly seen around thigh muscles, although other muscles could be affected with intermuscular, paraarticular and even subcutaneous subsets.

\section{Case report}

Patient, 70-year-old female with no relevant clinical history, presented with an incipient swelling on the posterior side of the left thigh. Plain x-ray showed a soft tissue thickening of the thigh with no bony lesions. MRI came back for a well-defined cystic tissue mass measuring $64 * 61 * 100 \mathrm{~mm}$ (figure 1a -b). The solid central component was enhanced on contrast medium injection. It was far from the femoral vessels and was closely linked to the large sciatic nerve anteriorly.

The patient underwent a surgical biopsy of the tumor for which histological examination returned for an intramuscular myxoma with no signs of malignancy.Patient subsequently underwent extensive tumor excision (figure 2; 3) and pathology confirmed myxoma. 15 months after treatment nolocal recurrence has been observed.

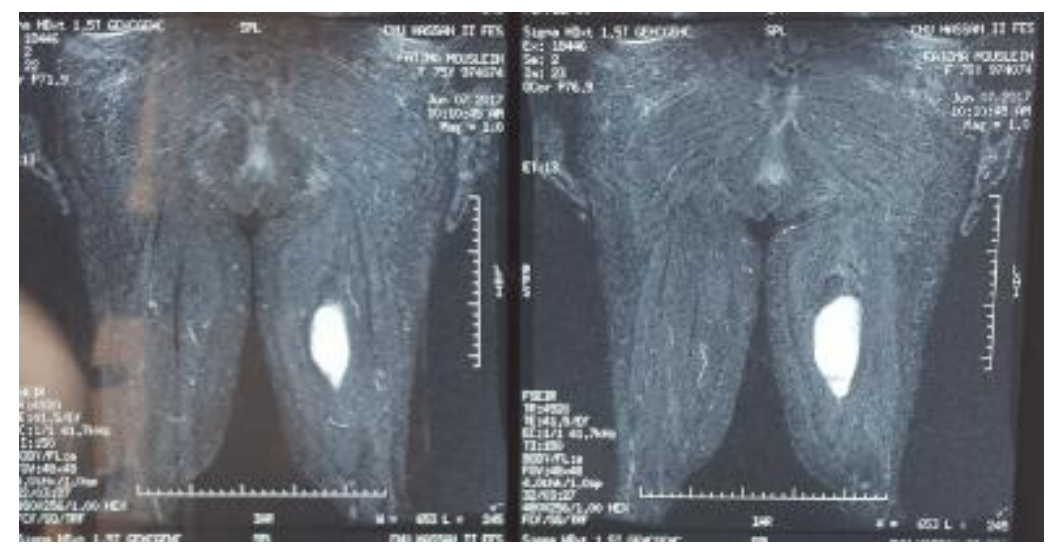

Fig 1a

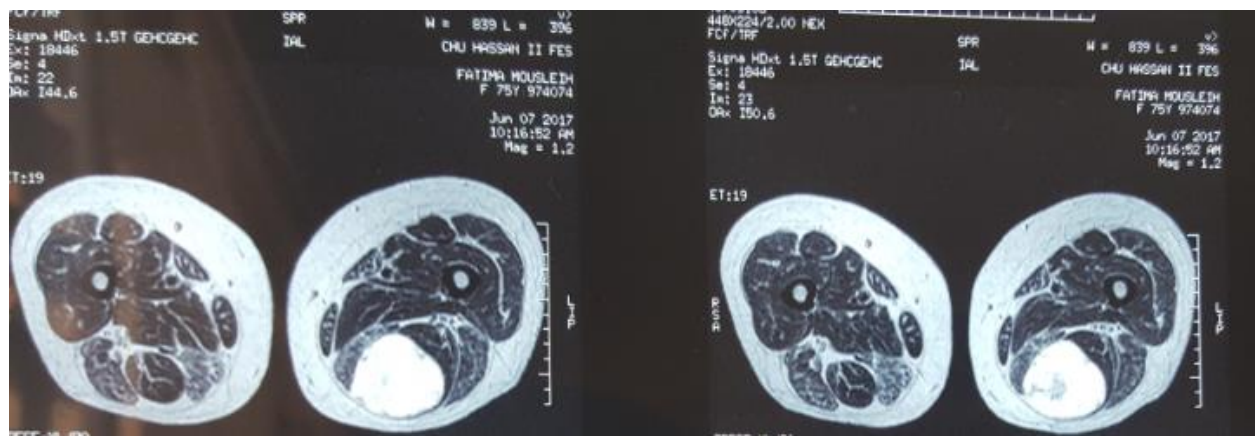

Fig 1b

Fig 1a- b: MRI showing cystic tissue mass measuring 64 * 61 * $100 \mathrm{~mm}$. The solid central component was enhanced on contrast medium injection

\section{Discussion}

Myxoma constitutes a benign tumor of mesenchymal origin composed of undifferentiated stellate cells within a myxoid tissue sometimes resembling that of the umbilical cord [1]. Besides cardiac muscle locations, skeletal muscle involvement is most common in the muscles of the thigh, but may affect other muscles and may be in intermuscular, para-articular or sometimes subcutaneous [1]. Women are commonly affected. The association of intramuscular 


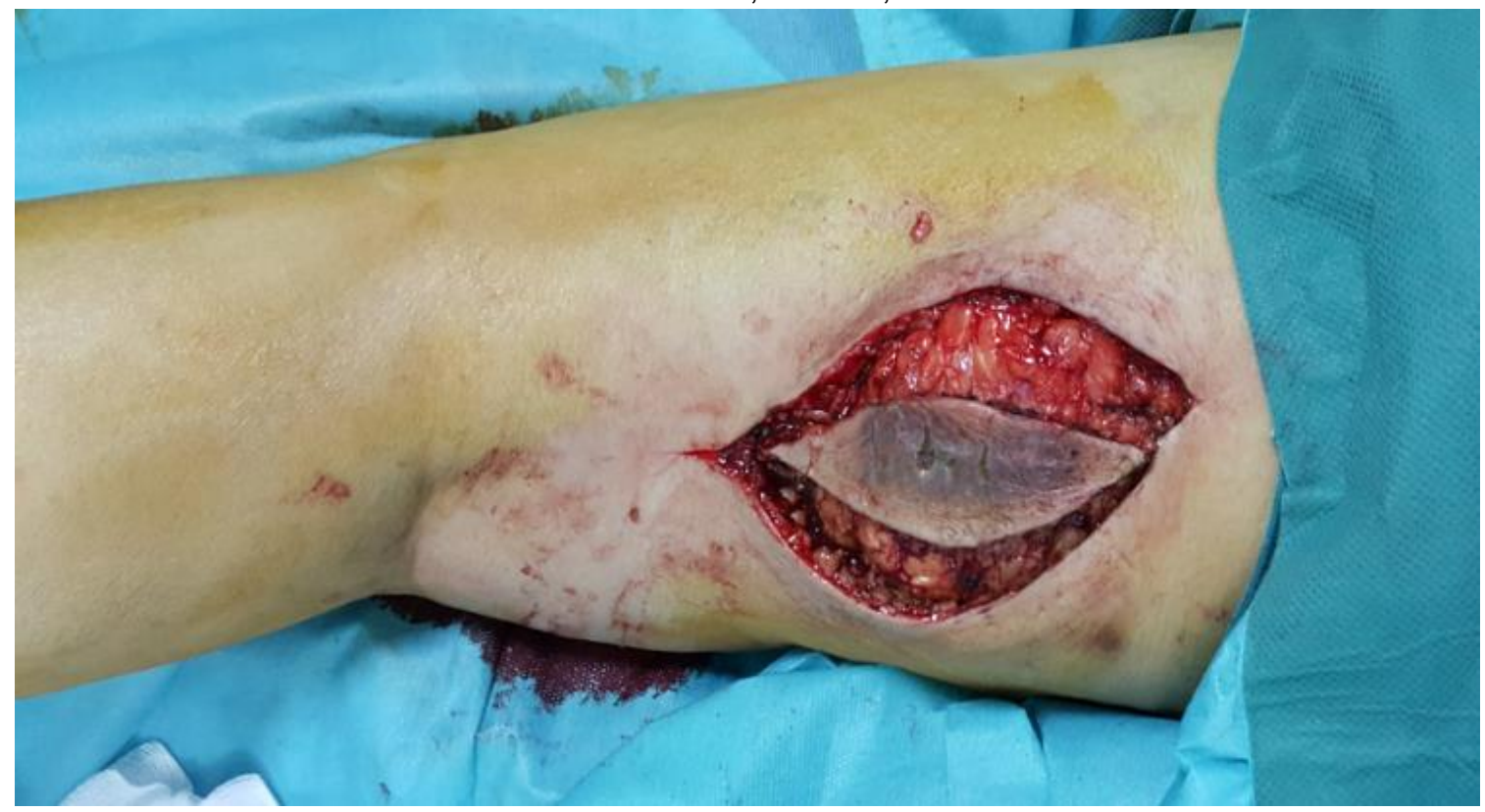

Fig 2: Extensive tumor excision

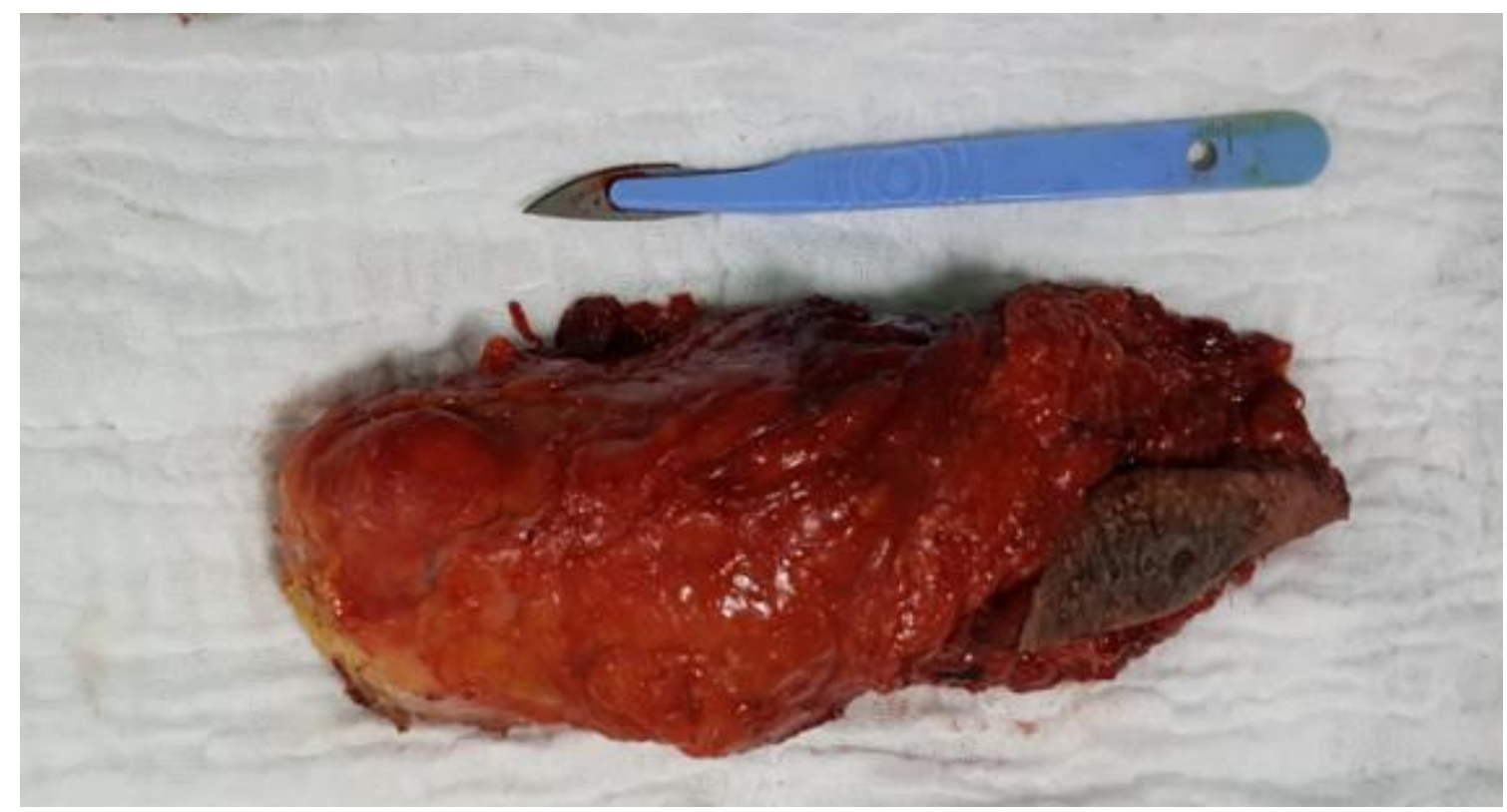

Fig 3: The tumor mass after excision

myxoma with fibrous dysplasia is termed Mazabraud syndrome [2]. In imaging, the lesion presents as an intramuscular cystic mass due to its high liquid density due to its predominant mucinous component and low collagen content. It appears hypodense on CT, hypo-intense on $\mathrm{T} 1$ and especially hyper-intense on T2 weighted sequences. The solid component of the tumor is often not visible on CT scan. It is best seen on ultrasonography [3], and MRI on T2-weighted sequences (hyposignal septa separating cystic zones) and T1-weighted sequences after gadolinium injection (heterogeneous lesion containing septa withdiffuse peripheral enhancement) [4]. . It is noteworthy that there is usually no calcifications within the lesion. The contours of the tumor are well limited; a pseudocapsule sometimes seen on ultrasound or MRI, rarely on the CT scan, and blood vessels only located outside the lesion. Myxoma is usually surrounded by a fatty ring often present at the upper and / or lower poles of the lesion thus depicting the bright rim and bright cap signbest seen on MRI. This fatty 
ring corresponds to an atrophy of the surrounding tumor muscle in direct contact with mucoid stroma, due to the absence of capsule or lack thereof. This phenomenon could also explain peritumoral edema, sometimes found on T2-weighted sequences in MRI $[1,5]$. The main differentials include synovial and mucoid cysts, neurogenic tumors, myxoid liposarcoma and myxofibrosarcoma. Synovial and mucoid cysts are usually intermuscular and arise at specific locations with imaging features rather more homogeneous and purely cystic. Neurogenic tumors are also often intermuscular with direct links to adjacent nerve and a typical "target sign" seldom seen on T2 sequences. Myxoid liposarcoma usually contains an intrinsic fat component. Finally, myxofibrosarcoma is often much more heterogeneous on imaging, with tissue componenthighly enhanced after contrast medium injection and often associated with hemorrhagic modifications [1]. Imaging features are rather less specific and remain insufficient to affirm positive diagnosis. Complete surgical excision is the mainstay as it guarantees no local recurrence and pathology examination allows definitive diagnosis of tumor [6].

\section{Conclusion:}

Intramuscular myxoma is a well-defined benign tumor whose definitive diagnosis could pose a challenge. MRI remains an essential tool in the preoperative workup. Major differentials includeliposarcoma, which could be myxoid in $50 \%$ of cases. Wide excision is highly recommended with no recurrences after surgery.

\section{References:}

1. Murphey M.D., McRae G.A., Fanburg-Smith J.C., Temple H.T., Levine A.M., Aboulafia A.J. Imaging of soft-tissue myxoma with emphasis on $\mathrm{CT}$ and MR and comparison of radiologic and pathologic findings Radiology 2002 ; 225 : 215224

2. Delabrousse E., Couvreur M., Bartholomot B., Lucas X., Kastler B. Syndrome de mazabraud : à propos d'un cas diagnostiqué en IRM $J$ Radiol 2001; 82 : 165-167
3. Girish G., Jamadar D.A., Landry D., Finlay K., Jacobson J.A., Friedman L. Sonography of intramuscular myxomas: the bright rim and bright cap signs J Ultrasound Med 2006 ; 25 : 865-871

4. Luna A., Martinez S., Bossen E. Magnetic resonance imaging of intramuscular myxoma with histological comparison and a review of the literature Skeletal Radiol 2005 ; 34 : 19-28

5. Bancroft L.W., Kransdorf M.J., Menke D.M., O'Connor M.I., Foster W.C. Intramuscularmyxoma: characteristic MR imagingfeatures $A J R$ Am J Roentgenol 2002 ; $178: 1255-1259$

6. Charron P., Smith J. Intramuscular myxomas: a clinicopathologic study with emphasis on surgical management Am Surg 2004 ; 70 : 1073-1077

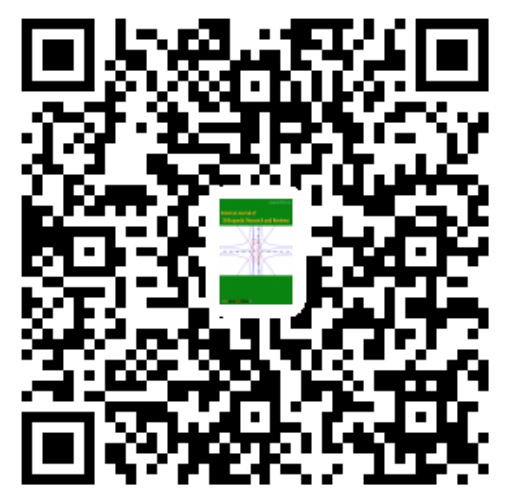

